\title{
MAQUIAVEL E TUCÍDIDES: O(S) OLHAR(ES) DA HISTÓRIA E AS FIGURAÇÕES DE HISTORIADOR
}

\author{
Francisco Murari Pires \\ Departamento de História - FFLCH/USP
}

\begin{abstract}
Resumo
O olhar da história tucidideana volta a plenificação de sua valia para o futuro, quer imediato quer longínquo, por que os homens desta temporalidade a reconheçam no presente de suas ações. Retirado em Sant'Andrea di Percussina, Maquiavel volta o olhar da história para o passado. Pelo circuito dos livros de seu escritório frequenta a Corte dos antigos. Refletindo sobre esse diálogo com os antigos, Maquiavel pondera o alcance do olhar que a história presente volta para o passado, a fim de que se mobilize recíproca interpelação de conhecimentos modernos e antigos sobre os modos por que nela agem os homens. Desde os inícios com Heródoto e Tucídides, o dilema da historiografia é posto: relatos verídicos contra mentirosos, neutralidade e isenção contra parcialidade e comprometimento. Por que as histórias são contadas a um público a que elas estão destinadas, como conformar modos narrativos para obter o reconhecimento da imparcialidade do historiador e veracidade de sua história:? Quais virtudes se exigem dele consoante as recomendações de preceitos e deveres narrativos que consagrem a autoridade de sua persona historiográfica? Por quais figurações retóricas de caracterização dessa persona de historiador Maquiavel e Tucídides enfrentaram o dilema assim disposto a responder pela utilidade a que esse saber almeja?
\end{abstract}


Em 1943, ao sabor das peripécias da guerra, Karl Reinhardt compôs um ensaio a que deu o título de Thukydides und Machiavelli. ${ }^{1}$ Ao longo de quase todo o texto ${ }^{2}$ analisa estritamente as concepções históricas de Tucídides em termos de Machtpolitik, para, então, retomar, já na conclusão, a lembrança do nome de Maquiavel. ${ }^{3}$ Pelas induções narrativas dessa intriga onomástica assim diversamente textualizada, insinua que, ao discorrer sobre Tucídides, falava (também) de Maquiavel!

Ao longo das análises por que evoluem no decurso do século XX seja a crítica dos estudos sobre Maquiavel seja sua congênere sobre Tucídides, a associação de um nome ao outro ganha nexos de irresistível automaticidade, como se compusessem figuras gemelares, de que a presentificação de uma sensibiliza e catalisa a da outra. $\mathrm{O}$ viés dominante desse zelo crítico tradicional concentra seus esforços de acuidade exegética em aferir a justeza, contra a impropriedade, da reprodução maquiaveliana dos informes tucidideanos. São quase todos concordes no apontar as imprecisões, os erros, os desvios, as deficiências e mesmo as deturpações com que Maquiavel (des)apreende Tucídides. ${ }^{4}$ Consequentemente, aventam-se que ordens de distúrbios teriam prejudicado o (des)entendimento de Tucídides por Maquiavel: ou porque o citasse de memória; ou porque o conhecesse apenas intermediado por outros textos e autores; ou, pior, porque o retorcesse visando à comprovação de suas próprias teses políticas. ${ }^{5}$ Empenhos, por diligentes que sejam em sua perícia crítica, duplamente problemáticos. Por um lado, porque de equívoca historicização, pois ajuizam a práxis intelectiva

\footnotetext{
${ }^{1}$ REINHARDT, Karl. Vermächtnis der antike. Gesammelte essays zur philosophie und geschichtsschreibung. Herausgegeben von Carl Becher. Göttingen: Vandenhoek \& Ruprecht, 1966, p. 184-218. ${ }^{2}$ Por cerca de 31 páginas do total de 35 que compõem o ensaio.

${ }^{3}$ Reinhardt refere-se à obra de Edward Schwartz: Charakertköpfe der antiken literatur na edição de Lepizig 1943, cuja primeira edição data de 1903. Eis o trecho citado por Reinhardt na tradução espanhola de J. R. Pérez Bances: “Tucídides es un historiador del tipo de Maquiavelo. Sólo le diferencia del florentino una circunstancia: su ciudad natal era un Estado grande y fuerte, mientras que Maquiavelo no veía ni en sua patria pequeña ni en la grande ningún Estado que pudiese compararse con las grandes potencias de esta época. Por eso el italiano del Renacimiento insiste demasiado en considerar la política como el arte de dominar a hombres y cosas gracias a la superioridad del entendimiento; mientras que el ateniense del siglo V comprendía que no puede pensarse en una gran politica sin una gran potencia". SCHWARTZ, Eduard. Figuras del mundo antiguo. Traducción del alemán por J. R. Pérez Bances. Madrid: Alianza Editorial, 1986, p. 34-35. ${ }^{4} \mathrm{O}$ fenômeno, dizem os críticos, não se restringe à leitura de Tucídides, antes compromete igualmente a apropriação que Maquiavel faz de outros autores clássicos, de que o exemplo mais expressivo seria Tito Lívio, assim analisado por Martelli para o texto dos Discorsi.

${ }^{5}$ CANFORA, Luciano. Tucidide l'oligarca imperfetto. Pordenone: Edizioni Studio Tesi, 1991, p. 36.
} 
de Maquiavel pelo padrão de medida de rigor crítico por que responde a (cons) ciência historiográfica firmada a partir do século XIX e desdobrada no XX, ${ }^{6}$ assim implicando que Maquiavel devesse conhecer (o texto de) Tucídides com o domínio que nós, entretanto, só contemporaneamente consolidamos. Por outro lado, porque camuflam um senso de pertinência analítica, todavia, algo duvidoso, quer porque tenha por desfecho antes ociosas controvérsias do que conclusões, quer porque, sobretudo, afirme ambiguamente sua (des)valia ao conscientizar uma problemática confiança na efetividade hermenêutica dessa operação crítica, assim a justificando como mediação analítica para a apreensão de uma inteligibilidade superior do texto, mas, efetivamente, a operando autonomamente como um fim em si mesma. ${ }^{7}$

Por tais concatenações exegéticas por que se conjecturam as falas com que Maquiavel (supostamente) dialogasse com Tucídides, a presença da influência autoral transita entre os textos de um e outro, imbricando as determinações recíprocas de seus correspondentes pensamentos. De modo que, por esse jogo hermenêutico, a consciência moderna tanto presentifica os aportes tucidideanos nas teorias maquiavelianas quanto, em contrapartida, opera a intriga no sentido inverso, a agora aventar o destino de pensamento político já moderno como que prenunciado pelo historiador antigo. Espécie de teleologia tautológica (e mutatis mutandis) por que tanto, de um lado, se aventam as (des)heranças tucidideanas de Maquiavel, quanto, de outro, se estigmatizam os anátemas maquiavelianos de Tucídides.

Afastando-nos de quaisquer pretensões de assim caracterizar ou a genealogia tucidideana de Maquiavel ou a correspondente teleologia maquiaveliana de Tucídides, a via hermenêutica que seguiremos intenta apenas compor um diálogo em paralelo das concepções de escrita da história em um e outro autor.

Ao firmar no proêmio de sua obra qual fosse a valia da história que ele narrava, Tucídides adverte contra os apelos que a desviassem pelas veredas sedutoras dos relatos mitificantes (tò mythõdes). ${ }^{8}$ Por tais modos narrativos, a escrita de histórias extraviava sua finalidade enquanto memorização de feitos

\footnotetext{
${ }^{6}$ Confiram-se nossas considerações tecidas já a respeito da análise moderna do valor "científico" da historiografia de Leonardo Bruni em PIRES, Francisco Murari. Modernidades tucidideanas. São Paulo: Edusp-Fapesp, 2007, p. 90-99.

${ }^{7}$ Emblemática, nesse sentido, a obra de Martelli. Confiram-se as indicações referidas em nosso ensaio sobre Maquiavel. MURARI PIRES, Francisco. A corte dos antigos e (o diálogo com) Tucídides. In: Antigos e modernos: diálogos sobre a (escrita da) história. Organizado por Francisco Murari Pires. São Paulo: Alameda-Capes-CNPq, 2009, p. 201-230.

${ }^{8}$ Tucídides I.22.4.
} 
humanos ao sacrificar a expressão da verdade dos acontecimentos em prol do agrado do público a quem fossem contadas. Ordenação da narrativa das ações dos homens pelos efeitos do mito que frustra a valia de suas histórias fazendo desvanecer, pelo deleite fugaz do presente, o aporte perene de saber a que almeja tal modalidade de memória humana.

Tucídides, pelo contrário, ordena sua narração pelo primado cognitivo da verdade dos fatos, apreendida graças à acribia de excelência ajuizante por historiador que se fundamenta pela autópsia fenomênica por que se presenciam os acontecimentos. A memorização das ações humanas ganha clarividência pela narração de uma história, a da Guerra dos Peloponésios e Atenienses, então cristalizada como saber. Dado que os homens, pelos modos próprios de sua natureza, assemelham suas ações no curso do tempo histórico, praticando-as tais quais ou análogas às do passado, a história, constituída como narração verídica, dispõe saber precioso (ktema es aei). O olhar da história tucidideana volta a plenificação de sua valia para o futuro, quer imediato quer longínquo, por que os homens desta temporalidade a reconheçam no presente de suas ações.

Retirado em Sant'Andrea di Percussina, Maquiavel volta o olhar da história para o passado. Pelo circuito dos livros de seu escritório frequenta a Corte dos antigos, com eles dialogando sobre as questões do Estado. Os ecos dessas conversas, todavia silentes, ressoam pelas reflexões que compõem os Discorsi, em que Maquiavel faz dialogar o presente florentino com o(s) olhar(es) que os antigos, com foco especialmente centrado em Tito Lívio, lançaram sobre a história. Refletindo sobre esse diálogo com os antigos, Maquiavel pondera o alcance do olhar que a história presente volta para o passado, a fim de que se mobilize recíproca interpelação de conhecimentos modernos e antigos sobre os modos porque nela agem os homens.

Que os homens exaltem e prefiram o passado em detrimento do presente compõe aceite de senso comum, como tal apreciado quer referido ao tempo histórico, geral e objetivo de experiência alheia, quer ao tempo biográfico, singular e subjetivo de vivência pessoal. ${ }^{9}$ Assim o fazem, adverte Maquiavel, quase sempre equivocadamente, iludindo-se pelos desatinos que afetam o senso

\footnotetext{
9 "Os homens sempre louvam - mas nem sempre com razão - os tempos antigos e reprovam os atuais: e de tal modo estimam as coisas passadas, que não só celebram as eras que conheceram graças à memória que delas deixaram os escritores, como também aquelas de que os velhos se recordam por as terem visto durante a juventude". MAQUIAVEL. Proêmio. In: Idem: Discursos sobre a primeira década de Tito Lívio II. São Paulo: Martins Fontes, 2007, p. 177.
} 
ajuizante dos homens. No âmbito da própria experiência pessoal, o senso se extravia porque contaminado pelas distintas paixões e valorativos afetos que os tomam no decorrer de suas vidas..$^{10}$ Já no âmbito do conhecimento alheio guardado por correspondentes relatos históricos, a razão humana se perde porque prejudicada pela inconsciência crítica. Os homens, que glorificam as histórias do passado, o fazem, todavia, inscientes de suas imperfeições e desvios, desatentos aos modos parciais por que se opera a memorização dos acontecimentos da Antiguidade, já que essas histórias que os contam conformam-se por discriminante axiologia glorificadora dos vencedores, tanto amplificando a grandiosidade de seus feitos virtuosos, quanto silenciando quaisquer infâmias que os deslustrem. E tanto mais se magnifica a fama dos vencedores quanto superem eles vencidos também formidáveis, de modo que os descendentes de uns e outros correspondentemente contentam-se e exultam com tais memórias. ${ }^{11}$

O passado antigo que os homens memorizam por suas histórias fulgura imagens de perfeição, ícones de veneração que entesouram, exteriormente a nós mesmos, nossos valores e ideais petrificados, estáticos como essas estátuas, ou apenas seus fragmentos, que adornam as casas modernas a figurarem modelos eternos de beleza. Os modernos tornam os antigos presentes em suas vidas como (se fossem) deuses, por obras e feitos de grandeza e perfeição tanto mais veneráveis quanto excepcionais, de (ir)realização encerrada no passado, inalcançáveis, impossíveis para os homens do presente. ${ }^{12}$ Os antigos, assim idealizados,

\footnotetext{
10 "O mesmo não deveria ocorrer com os velhos, quando julgam os tempos da juventude e os da velhice, uma vez que conheceram e viram igualmente aquelas e estas. Isso seria verdadeiro se, em todos os momentos da vida, os homens tivessem o mesmo tipo de julgamento e os mesmos desejos; mas, variando estes, mesmo quando os tempos não variam, os homens não podem ter dos tempos as mesmas impressões, visto terem desejos, predileções e considerações diferentes na velhice e na juventude”. MAQUIAVEL. Proêmio. Op. cit., p. 180).

11 "Nunca se conhece toda a verdade das coisas antigas, visto que, no mais das vezes, se escondem as coisas que infamariam aqueles tempos, magnificando-se e ampliando-se as outras coisas que podem glorificá-los. Porque a maioria dos escritores se atem de tal modo à fortuna dos vencedores que, para tornarem gloriosas as suas vitórias, não só aumentam aquilo que virtuosamente fizeram, como também magnificam as ações dos inimigos de tal modo que quem nascer depois em qualquer das duas províncias, na vitoriosa ou na vencida, terá razão para admirar-se daqueles homens e daqueles tempos, havendo de, forçosamente, louvá-los e amá-los". MAQUIAVEL. Proêmio. Op. cit., p. 177. 12 "Considerando, portanto, as homenagens que se prestam à antiguidade, o modo como muitas vezes - para não citar infinitos outros exemplos - um fragmento de estátua antiga é comprado por alto preço por quem deseja tê-lo consigo e com ele honrar sua casa, permitindo que seja imitado por quem se deleite com tal arte; considerando como os outros se esforçam por representá-lo com toda indústria em todas as suas obras; e vendo, por outro lado, que as virtuosíssimas ações que as histórias nos mostram, ações realizadas por reinos e repúblicas antigas, por reis, comandantes,
} 
figuram na história (equi)valendo por heróis, categoria originariamente grega de ambígua definição porque se (con)fundem homens e deuses. ${ }^{13}$

Por tais modos, adverte Maquiavel, os homens perdem a genuína valia da história, cegos a seu justo sentido e insensíveis a seu condizente deleite. ${ }^{14}$ Pois, a história, quer de antigos quer de modernos, os homens a fazem. E os homens de outrora são ainda os de hoje, como também o são "o céu, o sol, os elementos", mais "seu movimento, ordem e poder". ${ }^{15}$ A efetiva imitação do antigo pelo moderno deve conformar, sim, o télos da história, seu princípio e fim, o bem valioso disponibilizado como o(s) conhecimento(s) virtuosos que dos antigos aos modernos ela memoriza. Eis, diz Maquiavel, sua "descoberta", a senda não trilhada por que se vislumbre o novo continente até então inexplorado, ${ }^{16}$ o método inovador de reflexão sobre a história, qual seja, uma dialética em que passado antigo e presente moderno mutuamente interpelem suas razões ${ }^{17}$ aferindo modos virtuosos contra corruptos por que se afirma a utilidade da história. ${ }^{18}$ História, então, de axiologia e teleologia essencialmente

cidadãos, legisladores e outros que se afadigaram pela pátria são mais admiradas que imitadas; vendo, aliás, que a tais ações, em suas mínimas coisas, todos fogem, e que daquela antiga virtù não nos ficou nenhum sinal (...) quanto do fato de não haver verdadeiro conhecimento das histórias, de não se extrair de sua leitura o sentido, de não se sentir nelas o sabor que têm. Motivo porque infinitas pessoas que as leem sentem prazer em ouvir a grande variedade de acontecimentos que elas contêm, mas não pensam em imitá-las, considerando a imitação não só difícil como também impossível”. MAQUIAVEL. Proêmio. Op. cit., p. 5-7.

${ }^{13}$ MURARI PIRES, Francisco. Mithistoria. São Paulo: Humanitas, 1999, p. 92-93.

14 "E creio que isso não provém tanto da fraqueza à qual a atual religião conduziu o mundo, ou do mal que um ambicioso ócio fez a muitas regiões e cidades cristãs, quanto ao fato de não haver verdadeiro conhecimento das histórias, de não se extrair de sua leitura o sentido, de não se sentir nelas o sabor que têm". MAQUIAVEL. Proêmio. Op. cit., p. 6-7.

15 “"Como se o céu, o sol, os elementos, os homens tivessem mudado de movimento, ordem e poder, distinguindo-se do que eram antigamente". MAQUIAVEL. Proêmio. Op. cit., p. 7.

16 "Ainda que, devido à natureza invejosa dos homens, sempre tenha sido tão perigoso encontrar modos e ordenações novos quanto procurar águas e terras desconhecidas - por estarem os homens sempre mais prontos a censurar do que a louvar as ações alheias -, assim mesmo, levado pelo natural desejo que em mim sempre houve de trabalhar, sem nenhuma hesitação, pelas coisas que me pareçam trazer benefícios comuns a todos, deliberei entrar por um caminho que, não tendo sido ainda trilhado por ninguém, se me trouxer enfados e dificuldades, também me poderá trazer alguma recompensa, por meio daqueles que considerarem com humanidade os objetivos deste meu labor". MAQUIAVEL. Proêmio. Op. cit., p. 5.

${ }^{17}$ Assim também declarado especialmente na célebre carta a Vettori de 10 de dezembro de 1513. Confira-se ZANZI, Luigi. I segni della natura e i paradigmi della storia: Il método del Machiavelli. Maduria: Lacaita Editore, 1981, p. 35. Vejam-se ainda os comentários de GARIN, Eugenio. Dal Rinascimento all'Illuminidsmo. Studi e ricerche. Pisa: Nistri-Lischi, 1970, p. 48-49.

18 “Desejando, pois, afastar os homens desse erro, julguei necessário escrever, acerca de todos os 
política, atinente às questões do Estado que finalizem a promoção humana do bem comum. ${ }^{19}$ História por descortino político e Política de profundidade histórica, o saber inovador é assim disponibilizado aos que agenciam os destinos humanos no mundo terreno, quer príncipes quer repúblicas, oferecendo-lhes os exemplos da Antiguidade em que devem inspirar seus atos, bem discernindo virtudes contra vícios, a fugir destes e imitar aquelas. Tal o dever do homem sábio, diz Maquiavel: apontar o bom caminho. ${ }^{20}$

A 8 de novembro de 1520, Maquiavel recebia, por intermédio dos oficiais do Estudio Florentino, o encargo de compor "anais e crônicas de Florença", fixados seus estipêndios em cem florins. A ordem provinha de um Médici, Giulio, então cardeal.

Alguns anos depois, quer quando da redação do proêmio quer, a seguir, da carta em que dedica as Istorie fiorentini ao (já então) papa Clemente VII, o historiador de Florença revela por que nuances ele entendera as intrigas daquela comissão historiográfica que lhe fora encomendada. Os termos oficiais da mesma rezavam: "que eu escrevesse as coisas feitas pelo povo florentino". ${ }^{21}$ Desde o início de sua composição, entretanto, o historiador bem localiza o foco histórico especialmente induzido por seu precípuo patronato: os feitos dos Médici, ancestrais do pontífice, senhores de Florença.

Narrar, então, os feitos dos Médici. Obra, todavia, de encargo historiográfico bem delicado e espinhoso, especialmente atentando-se às ordens do mandatário que a encomendara, as quais preceituavam que ele "descrevesse com justeza os

livros de Tito Lívio que não nos foram tolhidos pelos malefícios dos tempos, aquilo que, do que sei das coisas antigas e modernas, julgar necessário ao maior entendimento deles, para aqueles que lerem estes meus comentários possam retirar deles mais facilmente a utilidade pela qual se deve procurar o conhecimento das histórias". MAQUIAVEL. Proêmio, Op. cit., p. 7.

${ }^{19}$ Como atuar "na ordenação das repúblicas, na manutenção dos estados, no governo dos reinos, na ordenação das milícias, na condução da guerra, no julgamento dos súditos, na ampliação dos impérios". MAQUIAVEL. Proêmio. In: Idem: Discursos sobre a primeira década de Tito Lívio. I, São Paulo: Martins Fontes, 2007, Op. cit., p. 6).

20 "E, realmente, se a virtù que então reinava e o vício que agora reina não fossem mais claros que o sol, eu seria mais contido no que digo, evitando incorrer no erro de que acuso alguns. Mas, sendo a coisa tão manifesta, que qualquer um pode vê-la, serei ousado e direi manifestamente tudo o que pensar sobre aqueles tempos e estes, para que os ânimos dos jovens que lerem estes meus escritos possam fugir a estes tempos e preparar-se para imitar aqueles, sempre que a fortuna lhes der a ocasião. Porque é dever do homem bom ensinar aos outros o bem que a malignidade dos tempos e da fortuna não lhes permitiu realizar, a fim de que, sendo muitos os conhecedores, alguns destes, mais amados pelo Céu, possam realizá-lo". MAQUIAVEL. Proêmio. Op. cit., p. 180-181).

21 "che io scrivesse le cose fatte da il popolo fiorentino". MACHIAVELLI, Niccolò. Istorie fiorentine. A cura di Franco Gaeta. Milano: Feltrinelli Editore, 1962, p. 65. 
feitos de seus ancestrais de modo que não transparecesse qualquer adulação, pois, se lhe era agradável ouvir louvores verazes, desagradava-o ouvir falsos com o fito de obter favores". ${ }^{22}$ A interpelação Médici, ao interditar a adulação, mas na mesma medida recomendar o louvor, reclamava, portanto, do historiador dons de delicada perspicácia de juízo historiante, porque assim bem satisfizesse as injunções de uma tão direta quão enviesada ordem que desafiavam a inteligência de sua arte historiográfica. A história dos Médici supõe louvores, ça va de soi! $\mathrm{E}$, todavia, por quais aparências de veracidade os leitores discernem louvores insuspeitos de, ao contrário, adulações indignas, tanto mais em uma história, entretanto, que se via comprometida desde o princípio por nexos patronais virtualmente condenatórios? Arte historiográfica a requerer do historiador refinada sensibilidade de discernimento com que seu juízo mantém-se afastado da adulação sem, no entanto, deixar extraviar-se o louvor. Compromisso historiográfico de complexa exigência narrativa por que o historiador tanto preserve a dignidade de seu ofício quanto afiance a veracidade de sua história.

Por todos os modos e recursos de sua arte retórica, Maquiavel empenha-se em livrar sua história do fantasma daqueles nexos que assombram a apreciação ajuizante de seu serviço historiográfico: veracidade deturpada por desastrosa adulação, a arruinar-lhe os favores do ofício. A enfrentar as atribulações do desafio, o historiador formula, como contrapartida conceitual da adulação, meritória lisonja que, antes dignificando a história, persuadisse a boa recomendação de seus préstimos. Por um jogo de sutil inteligência por que ele constrói a persuasão da honorabilidade verídica que recomendava sua obra, Maquiavel então volta contra o público leitor que a ajuizasse o mesmo dilema que o vitimava. Ele avoca então o argumento de que também sobre eles, os leitores, impendiam os envolvimentos comprometedores de consoantes (des)apreços por que definissem seus votos judicantes. Assim ele o declara dirigindo-se ao papa: “Assim, Santíssimo e Beatíssimo Padre, empenhei-me nestas minhas descrições em, não maculando a verdade, satisfazer a todos; mas talvez não venha a satisfazer a ninguém e, se assim for, não me admirarei, pois considero impossível deixar de ofender a muitos quando descrevemos as coisas dos seus

\footnotetext{
22 "E perché dalla V.S. Beatitudine mi fu imposto particularmente e comandato che io scrivessi in modo le cose fatte da'Suoi maggiori, che si vedessi che io fussi da ogni adulazione discosto (perché quanto vi piace di udire degli uomini, tanto le finte e a grazia descritte le dispiaccino)". MACHIAVELLI, Niccolò. Istorie fiorentine. A cura di Franco Gaeta. Milano: Feltrinelli Editore, 1962, p. 65-66.
} 
tempos". ${ }^{23}$ Porque os tempos descritos pela história envolvem também as (des) razões dos próprios leitores, desvirtua-se a correção de seus juízos consoante a (in)satisfação das precípuas subjetividades que comprometem suas distintas expectativas pessoais: esperam eles da história ouvir verdades, mesmo que elas os ofendam, ou preferem mentiras, desde que os honrem ${ }^{24}$

Donato Gianoti revela ter Maquiavel lhe confidenciado o modo capcioso por que ele incorporara em sua história dizeres adversos aos Médici, assim cuidando para que não se acusassem tais espinhosos comprometimentos em seu nome: "direi o que aconteceu quando Cosmo tomou o poder, mas não direi de que modo e com que meios alcançou tal supremacia. Quem quiser entender isto, atente muito bem àquilo que eu farei dizer seus adversários, pois, o que eu não quiser dizer em meu nome, o farei dizer seus adversários". ${ }^{25}$

Já numa carta ${ }^{26}$ a Francesco Guicciardini, o próprio Maquiavel, ao advertir os imbroglios delicados daquele seu empreendimento historiográfico, ironiza a resolução de tais dilemas de (des)controladas "ofensas" eventualmente suscitadas por seus modos narrativos, assim oferecendo ao amigo "dez soldos, mas não mais" para que este lhe apontasse quais fossem os destemperos inconvenientes de sua narração. ${ }^{27}$

Ainda por essa época de composição das Istorie fiorentini, Maquiavel revela, em outra carta, ${ }^{28}$ os modos porque ele amadurecera as cautelas de sua inteli-

\footnotetext{
23 "Io mi sono pertanto ingegnato, Santissimo e Beatissimo Padre, in queste mia descrizione, non maculando la verità, di satisfare a ciascuno; e forse non arò satisfatto a persona; né, quando questo fusse, me ne maraviglierei, perché io giudico che sia impossibile, sanza offendere molti, descrivere le cose de' tempi suoi".

${ }^{24} \mathrm{O}$ tópos retórico é análogo ao tucidideano do Discurso fúnebre de Péricles, já por nós analisado em obra anterior (Murari Pires, 1997, p. 287-290).

25 “... io dirò i casi che successero quando Cosimo prese lo stato; ma non dirò in che modo e con che mezzi uno pervenga a tanta altezza. E chi vorrà anco intendere questo, noti molto bene quello ch'io farò dire ai suoi avversari, perché quello che non vorrò dire io, come da me, lo farò dire ai suoi avversari". Citado por Franco Gaeta. MACHIAVELLI, Niccolò. Istorie fiorentine. A cura di Franco Gaeta. Milano: Feltrinelli Editore, 1962, p. 48.

${ }^{26}$ De 30 de agosto de 1524.

27 "Ho atteso et attendo in villa a scrivere la istoria, e pagherei dieci soldi, non voglio dir piú, che voi fosse in lato che io vi potesse mostrare dove io sono, perché, avendo a venire a certi particulari, arei bisogno di intendere da voi se offendo troppo o con lo esaltare o con lo abbassare le cose; pure io mi verrò consigliando, et ingegnerommi di fare in modo che, dicendo il vero, nessuno si possa dolere". MACHIAVELLI, Niccolò. Opere. III Lettere. A cura di Franco Gaeta. Torino: Unione Tipografico-Editrice Torinese, 1984, p. 539. As razões de (in)veracidade da história assim declaradas por Maquiavel acertam-se, pois, consoante as sutilezas expressivas de confissões retóricas apropriadas a quais missivistas se as dirige.

${ }^{28}$ Também dirigida a Francesco Guicciardini.
} 
gência, agora resguardando-se contra as mazelas de dissabores e adversidades suscitadas por eventuais descontroles incriminatórios de suas posições: “de uns tempos para cá, eu não digo mais aquilo que eu creio, e nem creio mais aquilo que eu digo, e se eventualmente me ocorre dizer alguma verdade, eu a escondo entre tantas mentiras que é difícil encontrá-la". ${ }^{29}$

Pelo jogo ambíguo por que ele tanto (des)diz quanto (des)crê seus pensamentos, tanto mais que quando por eles expressa alguma verdade, a torna, todavia, indiscernível por que perdida, confundida em meio a mentiras que a rodeiam, Maquiavel tece o véu retórico com que, embaralhando os registros dos traços identificadores, confunde os comprometimentos de sua pessoa. Discriminação de verdade contra mentiras configura convicção apenas de quem detém o poder da palavra que diz a história, pois se a resguarda oculta pelo segredo do arbítrio e querer (dis)simulado porque o historiador a (in)define.

Maquiavel, ao dizer os modos personalizados desse espírito que então o toma nos tempos de composição das Istorie fiorentini, evoca competência estritamente humana de inteligência astuciosa de sua escrita, pois nela se trama um jogo (dis)simulado de verdades e mentiras confundidas. As figurações de sua arte de historiador, então, guarda equivalência com aquela que Hesíodo afirmava ser o apanágio próprio do poder divino figurado pelas Musas que detêm o mistério do canto historiante enquanto memória narrativa de saber factual: "sabemos muitas mentiras dizer símeis aos fatos, e sabemos se queremos dar a ouvir verdades". ${ }^{30}$ E guarda também equivalência com a virtuosidade que a Odisséia distinguia como característica das histórias contadas pela figura nomeada Odisseu, ${ }^{31}$ enquanto correspondente excelência heróica de memória

\footnotetext{
29 "da un tempo in qua, io non dico mai quello che io credo, né credo mai quel che io dico, e se pure e' mi vien detto qualche volta il vero, io lo nascondo fra tante bugie, che è difficile a ritrovarlo". MACHIAVELLI, Niccolò. Niccolò Machiavelli a Francesco Guicciardini, Carpi 17 maggio 1.521, carta 270. Opere. III Lettere. A cura di Franco Gaeta. Torino: Unione Tipografico-Editrice Torinese, 1984, p. 522. Já Giulio Ferroni destaca esta passagem da carta a Guicciardini como traço caracterizador do pensamento e modo de concepção política maquiaveliana, aproximandoa, por um lado, da tradição de "realismo prático, cômico e popular" da tradição florentina que pela figuração da "máscara" opera o "jogo duplo" da "(dis)simulação" porque (des)vela os nexos imbricados pela (in)consciência de "realidade" versus "aparência"; e, de outro, com "a cultura humanista" de seu tempo, assimilando-a pela figuração do "Sileno de Alcibíades" concebida por Erasmo de Roterdã (FERRONI, Giulio. Machiavelli, o dell'incertezza. La política come arte del rimedio. Roma: Donzelli Editore, 2003, p. 19-23).

${ }^{30}$ Teogonia v. 27-28 (pela tradução de Jaa Torrano ligeiramente modificada). Confira-se a análise do texto hesiódico em MURARI PIRES, Francisco. Mithistória. São Paulo: Humanitas, 1999, p. 246-248. ${ }^{31}$ Uma figuração odisséica de Maquiavel é também proposta por Ugo Dotti que o intitulou "Ulisses
} 
narrativa e saber factual: dizia "semelhas verdades e mentiras". ${ }^{32}$ Em última instância, a questão da verdade da história narrada no âmbito do discurso mítico, aqui apreciada enquanto narrativa do herói, remete para o arbítrio do sujeito que a narra, em conformidade com a ordem total de seus deveres éticos de honorabilidade nobilitadora. ${ }^{33}$

Desde o princípio com Heródoto, porque o lógos se sobreponha ao mito como fundamento discursivo de civilização, o dilema da historiografia se configura: relatos verídicos contra mentirosos, isentos contra parciais, como firmar a dignidade distintiva da história por que se memorizem as realidades dos feitos, das obras e dos modos com que nela agem os homens? Por que as histórias se contam tendo em vista um público a que elas se dirigem, como deve o historiador conformar modos narrativos que assegurem convicção de veracidade para as coisas que ele relata como fatos reais? Que virtudes excepcionais lhe são exigidas por recomendação de preceitos e deveres que consagrem a autoridade de sua narração?

Mas a apreensão da verdade do fato unívoco, adverte Tucídides, é obra penosa. Reclama ingente empenho de inteligência para resolver a aporia intrínseca de sua consecução, pois, para tanto, o historiador se defronta com a dialética inconciliável dos relatos conflitantes apresentados pelos que presenciaram os acontecimentos e, consoantemente, os informaram. Supõe sujeito humano dotado de espírito superior, distinguido por excelência de plena maturidade experiente

da política". Assim o fez, todavia, qualificando por tal nomeação o espírito de "curiosidade" que instiga e fundamenta o cabedal cognitivo acerca dos modos humanos por que também responde a figura do herói antigo: "la silhouette d'un homme, d'une insatiable 'curiosité'sur ses semblables, sur leurs stratégies intentionnelles ou leurs actions réelles et concrètes, d'un profond connaisseur de toute la lourdeur des liens inextricables unissant la tradition et la 'morale', d'un homme qui peut à juste titre mériter le titre de véritable". DOTTI, Ugo. Ulysse de la politique. La révolution Machiavel. Traduit de l'italien par Rebecca Lenoir et présenté par Frank La Brasca. Grenoble: Éditions Jérôme Millon, 2003, p. 14.

${ }^{32}$ Odisséia XIX.203. A abordagem desta aproximação da figuração maquiaveliana de historiador odisséico dialogada com a conceituação hesiódica de memória narrativa e saber factual nomeada Musas mais a homérica nomeada Odisseu será retomada e desdobrada em obra futura (Clio tucidideana) em que trataremos do similar diálogo ensejado pelas reflexões que La Popelinière propõe em L'idée d'histoire accomplie. Então completaremos o paralelo de figuração de historiador que o modo tucidideano de escrita da história projeta, mais propriamente nestoriano, abordagem esta já avançada em nossa obra anterior, a primeira das Modernidades tucidideanas. MURARI PIRES, Francisco. Modernidades tucidideanas. São Paulo: Edusp-Fapesp, 2007, p. 189-198.

${ }_{33}$ Argumentaremos todas as considerações aqui externadas sobre as figurações míticas de memória narrativa e saber factual nomeadas conceitualmente Musas e Odisseu em obra vindoura Clio tucidideana. 
que a razão capacita, de modo a poder discernir toda a verdade que desaparece confundida por essa dialética informativa. Via de trajeto difícil, percurso penoso de ingentes trabalhos, restrito a um único caminho que conduz justo à descoberta da verdade do fato. Via de conhecimento histórico própria a um destino pessoal heróico por areté de intelecto excepcional, privilégio de um indivíduo cujo nome chancela a obra por seu primeiro termo declarativo: Tucídides de Atenas. ${ }^{34}$

Similarmente o dá a entender Luciano listando o acúmulo de virtudes reclamadas por que se almeje escrever história excelente. ${ }^{35}$ Ser historiador requer tanto pessoa provida de complexo de virtudes excepcional por domínio absoluto de paixões, (res)sentimentos e (des)afetos, quanto indivíduo cuja situação no mundo pode mais propriamente ser dita inexistencial, pois intriga pertinência a um lugar, dito a-polis, que antes o desvincula do mundo humano, situa-o fora porque acima dele, sobrepairando as histórias de seus acontecimentos, como o olhar de Zeus. Ideal que, pois, configura persona de qualificação divina, na medida em que se concebe sua ideia por atributos definidos por negação de modos e aspectos inerentemente humanos.

No horizonte de historicidade do pensamento antigo, a categoria do heróico responde por essa (con)fusão de humano com divino porque ganha inteligibilidade a projeção de tal persona de historiador ideal. Nesse sentido, a distinção de dignidade historiográfica figurada por Tucídides aproxima-o propriamente da excelência de arte discursiva que tem, em Homero, por nome conceitual Nestor. Especialmente na cena da querela entre Agamêmnon e Aquiles, a figura do venerando conselheiro atua particularmente em função judicante, pois que discerne a decisão que acerta a dialética das (des)razões de duas partes em conflito. Similarmente a como também o poeta memoriza na cena do escudo de Aquiles, conselheiro vale por histor. ${ }^{36}$

\footnotetext{
${ }^{34}$ Confiram-se os argumentos por que tecemos estas considerações em nossos textos anteriores listados na bibliografia.

${ }^{35}$ LUCIANO. Como escrever história 41. In: HARTOG, François. A história de Homero a santo Agostinho. Tradução em português de Jacyntho Lins Brandão. Belo Horizonte: Editora UFMG, 2001, p. 224-231. Considerem-se ainda mais estas duas passagens: "Sobretudo, que seu pensamento se torne semelhante a um espelho impoluto, brilhante, preciso quanto a seu centro - e, qualquer que seja a forma dos fatos que recebe, assim os mostre, sem nenhuma distorção, diferença de cor ou alteração de aspecto"; “... de modo que se diga de ti: Aquele era seguramente um homem livre e totalmente franco, nada bajulador, nada de servil, mas verdadeiro em tudo" (LUCIANO, Como escrever história 50 e 61).

${ }^{36}$ Confiram-se nossos comentários já desenvolvidos em outro ensaio (MURARI PIRES, Francisco. 2003c, p. 113-5) em que procuramos aproximar as figurações (ditas) "metodológicas" da escrita
} 
$\mathrm{Na}$ intriga dessas heranças entre epopeia e história, o historiador então figuraria, correspondentemente a Nestor, como conselheiro cuja narrativa dos fatos acontecidos, assim acertados univocamente a superar a dialética conflitante dos relatos parciais e comprometidos que os relataram, responde pelo discurso sapiencial que reitera os preceitos da ordem política por singulares modos nestorianos de saber historiante, assim heroicizante. ${ }^{37}$

$\mathrm{Na}$ terceira edição de seu tratado Iconologia (Roma, 1603), Cesare Ripa define a figura de Clio pela conjugação de três ícones nucleares por que se a represente imageticamente: uma coroa de louros à cabeça, uma trombeta segura pela mão direita e um livro pela esquerda, em que se registram os feitos dos homens, passados e presentes, assinalando, pois, a história, atributo dessa Musa. Mas ícone este que comporta uma precisão: o livro é de Tucídides, por nome nele inscrito ${ }^{38}$ A razão de tal privilégio onomástico com que se honre condignamente a história: por que Tucídides, historiador famoso. ${ }^{39}$

Praticamente contemporânea dessa figuração de uma Clio tucidideana por Cesare Ripa, La Popelinière firma, na Histoire des histoires (Paris, 1599), similarmente a fama maior de Tucídides, então o intitulando Príncipe da História. ${ }^{40}$ Três décadas antes (1566), Jean Bodin também proclamara, no Methodus, que não Heródoto, mas sim Tucídides, devesse ser tido por o mais verdadeiro pai da históriaa ${ }^{41}$ Três décadas depois (1629), Thomas Hobbes, em sua tradução

da história tucidideana justamente das correspondentes figurações de atuação judicante do histor arcaico. Retomaremos a abordagem dessas configurações historiantes, especialmente assimilando historiador e juiz, em diálogos a serem encetados na sequência das obras que compõem nosso atual projeto de publicações.

${ }^{37}$ Para esta caracterização da figura de heroicidade com que o historiador recomenda sua obra, vejam-se nossos comentários no artigo já citado (2003c, p. 132).

38 "Rappresentaremo Clio donzella con una ghirlanda di lauro, che con la destra mano tenghi una tromba et con la sinistra un libro che di fuora sia scritto Tucidides".

39 “Si dipinge con il libro Tucidides, percioché attribuendosi a questa Musa l'historia, dicendo Virg. in opusc. de Musis: Clio gesta canens transacti tempora reddit. Convien che ciò si dimostri con l'opere di famoso Historico, qual fu il detto Tucidide".

40 "Il est sans controverse dict le Prince de l'Histoire: pour la beauté du langage et verité du narré: quelque chose que dit Ciceron d'Herodote qu'il luy prefere. Et Denys d'Halic. au jugement qu'il fait du merite de celuy ci'. LE POPELINIÈRE. L'Histoire des histoires. L'idée de l'histoire accomplie. Tome IV. Paris: Fayard, 1989a, p. 143.

41" But lest these things should seem like fables, let us rather agree with Thucydides, the most truthful father of history. He left witness that a little before his time such was the barbarity and the ferocity of men in Greece itself that by land and sea piracy was openly practiced. Without any shame travellers usually asked whether those they encountered were robbers or pirates or not. Yet since fortifications did not exist at that time and there were no defenses, justice resided 
de Tucídides, consagra fórmula de similar fama historiográfica, mas já por teores reflexivos mais precisamente direcionados: Tucídides, "the most politic historiographer that ever writ". ${ }^{42}$ Por todas essas celebrações da memória de Tucídides enquanto ideal ou modelo historiográfico, ela assim comparece em figuração de sabedoria ajuizante, similar à heroicidade nestoriana, que resolve os conflitos e divergências porque situada acima dos partidos e facções.

Por tais projeções de excelência historiográfica por que o nome de Tucídides emblematize a escrita da história do século XVI para o XVII, a persona do historiador é apreciada por enredamentos de intrigas agonísticas com seus pares antigos. Por uma delas, que avança de La Popelinière a Hobbes, subjaz um agón com Tácito, ou mais precisamente com o tacitismo, avatar de maquiavelismo de fins do XVI. Por outra intriga agonística, agora de Tucídides com Heródoto, remonta-se de La Popelinière a Bodin, por meados do século. E, por Bodin, com as intrigas dessa agonística pondo em paralelo Tucídides e Políbio, o diálogo remonta a Maquiavel.

Por tais diálogos de modernos e antigos, a identidade da história ao longo do século XVI para inícios do XVII, de Maquiavel a Hobbes, ao instaurar a exemplaridade tucidideana de sua escrita, transita os modos de seu saber dos domínios da arte retórica para os da ciência política. Em tempos inaugurais da modernidade, pelo que assim diz Maquiavel ou pelo que similarmente imagina Bruegel em Paisagem com a queda de Ícaro, ${ }^{43}$ refigura-se o heróico herdado do imaginário da Antiguidade clássica. Por tais jogos retóricos situando nexos figurativos entre humano e divino, querer e poder, retomados dos antigos por que os modernos refletem sobre os dilemas da escrita da história, indecide-se o nexo conceitual que, dizendo da excelência superlativa do historiador, ordena a epistemologia da ou arte ou ciência do discurso historiográfico, assim vacilante no trânsito entre sua apreensão pelo evanescente conceito antigo do heróico e o moderno do gênio, então apenas florescente. ${ }^{44}$

in force, and the old colonists were continually driven from possession by new ones. This custom in Greece little by little became permanent". BODIN, Jean. Method for the easy comprehension of history. New York: W. W. Norton \& Company, 1969, p. 298.

42 "But Thucydides is one, who, though he never digress to read a lecture, moral or political, upon his own text, nor enter into men's hearts further than the acts themselves evidently guide him: is yet accounted the most politic historiographer that ever writ". HOBBES, Thomas. Hobbes's Thucydudes. New Brunswick: Rudgers University Press, 1975, p. 7.

${ }^{43}$ PIRES, Murari (2001b, p. 102-114).

${ }^{44}$ A questão é abordade em BRANN, Noel L. The debate over the origin of genius during the 


\section{Referências bibliográficas}

BODIN, Jean. Method for the easy comprehension of history. Translated by Beatrice Reynolds. New York: W. W. Norton \& Company, 1969.

BRANN, Noel L. The debate over the origin of genius during the Italian Renaissance. Leiden: Brill, 2002.

CANFORA, Luciano. Tucidide l'oligarca imperfetto. Pordenone: Edizioni Studio Tesi, 1991.

DOTTI, Ugo. Niccolò Machiavelli. La fenomenologia del potere. Milano: Feltrinelli Editore, 1979.

DOTTI, Ugo. La révolution Machiavel. Traduit de l'italien par Rebecca Lenoir et présenté par Frank La Brasca. Grenoble: Éditions Jérôme Millon, 2003.

FERRONI, Giulio. Machiavelli, o dell'incertezza. La politica come arte del rimedio. Roma: Donzelli Editore, 2003.

GARIN, Eugenio. Dal Rinascimento all'Illuminismo. Studi e ricerche. Pisa: NistriLischi, 1970.

HARTOG, François. A história de Homero a santo Agostinho. Prefácios de historiadores e textos sobre história reunidos e comentados por François Hartog, traduzidos para o português por Jacyntho Lins Brandão. Belo Horizonte: Editora UFMG, 2001.

HESÍODO. Teogonia. A origem dos deuses. Estudo e tradução por Jaa Torrano. $3^{\text {a }}$ edição. São Paulo: Iluminuras, 1995.

HOBBES, Thomas. Hobbes's Thucydides. Edited with an introduction by Richard Schlatter. New Brunswick: Rutgers University Press, 1975.

HOMERO. Odisséia. Tradução de Frederico Lourenço. Lisboa: Livros Cotovia, 2005 [2003].

La POPELINIÈRE. L'histoire des histoires. L'idée de l'histoire accomplie. Tome premier. Paris: Fayard, 1989.

La POPELINIÈRE. L'histoire des histoires. L'idée de l'histoire accomplie. Tome second. Paris: Fayard, 1989.

MACHIAVEL. Oeuvres complètes. Texte présenté et annoté par Edmond Barincou. Paris: Gallimard, 1952.

MACHIAVEL, Nicolas. Discours sur la première décade de Tite-Live. Traduction d'Alessandro Fontana et Xavier Tabet, préface d'Alessandro Fontana, et notes d'Alessandro Fontana (avec la collaboration de Xavier Tabet). Paris: Éditions Gallimard, 2004.

MACHIAVELLI, Niccolò. The discourses of Niccolò Machiavelli. 2 v. Translated

Italian Renaissance. Leyden: Brill, 2002. 
from the Italian with an introduction and notes by Leslie J. Walker. London: Routledge and Kegan Paul, 1950.

MACHIAVELLI, Niccolò. Arte della guerra e scritti politici minori. A cura di Sergio Bertelli. Milano: Feltrinelli Editore, 1961.

MACHIAVELLI, Niccolò. Istorie fiorentine. A cura di Franco Gaeta. Milano: Feltrinelli Editore, 1962.

MACHIAVELLI, Niccolò. Il teatro e tutti gli scritti letterari. A cura di Franco Gaeta. Milano: Feltrinelli Editore, 1965.

MACHIAVELLI, Niccolò. Il principe e Discorsi sopra la prima deca di Tito Livio. Con introduzione di Giuliano Procacci e a cura di Sergio Bertelli. Milano: Feltrinelli Economica, 1977.

MACHIAVELLI, Niccolò. Opere. III lettere. A cura di Franco Gaeta. Torino: Unione Tipografico-Editrice Torinese, 1984.

MACHIAVELLI, Niccolò. Lettere a Francesco Vettori e a Francesco Gucciardini (1513-1527). A cura di Giorgio Inglese. Milano: Rizzoli, 1989.

MACHIAVELLI, Niccolò. Discorsi sulla prima deca di Tito Livio. A cura di F. Bausi. Roma: Salerno Editrice, 2001.

MACHIAVELLI, Niccolò. O príncipe. $2^{a}$ edição. Introdução de Isaiah Berlin, tradução, prefácio e notas de Lívio Xavier, em apêndice uma carta de Niccolò Machiavelli a Francesco Vettori. Rio de Janeiro: Ediouro, 2001.

MAQUIAVEL. Comentários sobre a primeira década de Tito Lívio. Tradução de Sérgio Fernando Guarischi Bath. Brasília: Editora Universidade de Brasília, 1979.

MAQUIAVEL. Discursos sobre a primeira década de Tito Lívio. Glossário e revisão técnica de Patrícia Fontoura Aranovich, tradução de MF, edição de texto de Karina Jannini. São Paulo: Martins Fontes, 2007.

MAQUIAVELO, Nicolás. Epistolario 1512-1527. Introducción, edición y notas de Stella Mastrangelo. México: Fondo de Cultura Económica, 1990.

MARTELLI, Mario. Machiavelli e gli storici antichi. Osservazioni su alcuni luoghi dei Discorsi sopra la prima deca di Tito Livio. Roma: Salerno Editrice, 1998.

MURARI PIRES, Francisco. A retórica do método (Tucídides I.22 e II.35). Revista de História 138, 1998, p. 9-16.

MURARI PIRES, Francisco. The rhetoric of method (Thucydides I.22 and II.35). Ancient History Bulletin 12.3, 1998a, p. 106-112.

MURARI PIRES, Francisco. Mithistoria. São Paulo: Humanitas, 1999.

MURARI PIRES, Francisco. A morte do heróico. In: ROSENFIELD, Kathrin H. Filosofia e Literatura: o trágico. Filosofia e política, III.1. Rio de Janeiro: Zahar, 2001, p. 102-114.

MURARI PIRES, Francisco. Tucídides: a retórica do método, a figura de autoridade 
e os desvios da memória. In: BRESCIANI, Stella e NAXARA, Márcia (orgs). Memória e (res)sentimento. Campinas: Editora da Unicamp, 2001, p. 95-128.

MURARI PIRES, Francisco. Thucydide et l'assemblée sur Pylos (IV.26-28): rhétorique de la méthode, figure de l'autorité et détours de la mémoire. The Ancient History Bulletin 17, 2003 , p. 127-148.

MURARI PIRES, Francisco. Prologue historiographique et proème épique: les principes de la narration en Grèce ancienne. Quaderni di Storia 58, iugliodicembre, 2003b, p. 73-94.

MURARI PIRES, Francisco. Thucydidean modernities: History between science and art. In: Brill's companion to Thucydides. Edited by Antonios Rengakos and Antonis Tsakmakis. Leiden-Boston: Brill, 2006, p. 811-838.

MURARI PIRES, Francisco. Modernidades tucidideanas. São Paulo: EduspFapesp, 2007.

MURARI PIRES, Francisco. Maquiavel, a corte dos antigos e (o diálogo com) Tucídides. In: Antigos e modernos: diálogos sobre a (escrita da) história. Organizado por Francisco Murari Pires. São Paulo: Alameda-Capes-CNPq, 2009, p. 201-230.

REINHARDT, Karl. Vermächtnis der antike. Gesammelte essays zur philosophie und geschichtsschreibung. Herausgegeben von Carl Becker. Göttingen: Vandenhoek \& Ruprecht, 1966.

RIPA, Cesare. Iconologia overo descrittione di diverse imagini cavate dall'antichità et di propria inventione. Trovate et dichiarate da Cesare Ripa Perugino, cavaliere de Santi Mauritio et Lazaro. Di nuovo revista et dal medesimo ampliata di 400 et più imagini. Et di figure d'intaglio adornata. Opera non meno utile che necessaria a poeti, pittori, scultori et altri, per rappresentare le virtù, vitii, affetti et passioni humane. Appresso Lepido FaciiGeorg Olms, Roma, 1603. Biblioteca Virtuale on-line (http://bivio.signum.sns.it/).

SCHWARTZ, Eduard. Figuras del mundo antiguo. Traduccioón del alemán por J. R. Pérez Bances. Madrid: Alianza Editorial, 1986.

ZANZI, Luigi. I segni della natura e i paradigmi della storia: il metodo del Machiavelli. Ricerche sulla logica scientifica degli umanisti tra medicina e storiografia. Manduria: Lacaita Editore, 1981. 